\title{
RISCO E COMPLEXIDADE: A IMPUTAÇÃO DA RESPONSABILIDADE POR DANOS FUTUROS À LUZ DA TEORIA DOS SISTEMAS DE NIKLAS LUHMANN
}

\section{RISK AND COMPLEXITY: A DEDUCTION OF LIABILITY FOR FUTURE DAMAGES IN THE LIGHT OF THE THEORY OF SYSTEMS NIKLAS LUHMANN}

\author{
${ }^{1}$ Aline Klayse Dos Santos \\ Fonseca
}

\section{RESUMO}

O risco e a complexidade é uma realidade presente no meio social, todavia, ao mesmo tempo em que a sociedade contemporânea se complexifica mediante $\mathrm{o}$ desenvolvimento tecnológico, diferentes riscos são inobservados. Nesse sentido, as dimensões difusas dos danos e a sua projeção no tempo, ensejam mudanças na estrutura tradicional da responsabilidade civil, onde a incerteza e a complexidade devem fazer parte das observações das relações causais. O presente artigo busca analisar a contribuição da Teoria dos Sistemas de Niklas Luhmann para a dogmática jurídica, especificamente no âmbito da Responsabilidade Civil, sob a ideia de risco e complexidade, no que concerne a tomada de decisões um situações de causalidades não bem definidas, para a imputação de responsabilidade por danos futuros.

Palavras-chave: Risco, Complexidade, Responsabilidade civil

\begin{abstract}
The risk and complexity is a reality present in the social environment, yet at the same time that the contemporary society becomes more complex through technological development, different risks are unobserved. In this sense, diffuse dimensions of the damage and its projection in time, ensejam changes in the traditional structure of liability, where uncertainty and complexity should be part of the observation of causal relationships. This paper analyzes the contribution of the Theory of Niklas Luhmann's systems for legal doctrine, specifically under the Civil Liability under the idea of risk and complexity, with regard to decisionmaking of these situations of causalities not well defined for the allocation of liability for future damages.
\end{abstract}

Keywords: Risk, Complexity, Civil responsability

\footnotetext{
${ }^{1}$ Mestre em Química pela Universidade Federal do Pará - UFPA, Pará, (Brasil) Email: tutortreinamento@gmail.com
} 


\section{1- INTRODUÇÃO}

A configuração jurídica da Responsabilidade Civil apresenta uma evolução muito célere e, ao evoluir, deve apresentar soluções que atendam às novas necessidades sociais e de proteção à pessoa humana, sem, é claro, ir contra seus próprios limites que harmonizam o sistema jurídico. Isto decorre da pluralidade de sentidos que são atribuídos aos institutos jurídicos e por outras áreas do conhecimento científico, sendo fundamental revisar as premissas e os elementos da responsabilidade civil até às suas diversas funções.

O perigo de dano é indenizável? E há dano pela angústia ou pelo medo? É possível que a culpa do ofensor seja condição de imputação sem ser, ao mesmo tempo, um critério para a sua reparação? Como se vê ao mesmo tempo em que a Responsabilidade Civil assumiu papel de destaque de tensões sociais, nunca forneceu panorama tão sombrio quanto à certeza do direito.

Em verdade, a incerteza reina em todos os níveis de qualificação: à maleabilidade de seus conceitos internos se soma à indagação de suas funções e a disciplina aparece cingida entre a sua acessão contínua e a austeridade teórica de suas condições, entre a exigência do caso concreto e a regra de abstração. Com isso, cresce também os anseios de uma sociedade de vítimas, emotivamente aflita de punição e racionalmente apetecida por prevenção.

A sociedade de incertezas se constitui também como a sociedade de riscos decorrente dos processos de modernização autônoma, cujas ameaças escapam à percepção sensorial e ao próprio domínio do conhecimento científico. Percebe-se a perda da concretude das relações jurídicas, onde já não se sabe ao certo quem é comprador, vendedor, financiador, isto é, o próprio negócio se torna complexo o bastante, e por vezes é necessário remontar a cadeia causal para saber qual operação comercial the deu origem.

A complexidade e a incerteza da sociedade atual coloca em xeque, inclusive, o pressuposto fundamental da existência humana, dada as incertezas que inundam a produção técnicocientífica, que causam danos igualmente incertos, já que a dimensão espaço-temporal dos danos é nova e as lesões não são mais pontuais, imediatas e o tempo de vida do ser humano não coincide mais com a temporalidade dos danos (LEVY, 2012, p. 15)

É nesse contexto, a responsabilidade surge como instrumento de segurança e através de mecanismos de redução da cadeia causal, podem restringir a complexidade a fim de tutelar 
bens, interesses e a própria pessoa humana. Isso porque, nem sempre a causa de um evento é identificada com facilidade em razão da pluralidade de circunstâncias que se entrelaçam n realidade fenomênica de sua ocorrência, e, uma vez se olhando de perto, as causalidades são sempre complexas, múltiplas e entrelaçadas (CRUZ, 2005, p.19).

Nesse sentido, o presente artigo será desenvolvido a partir do método de pesquisa qualitativa, através da técnica de pesquisa e revisão bibliográficas, sendo fundamentado através da teoria do direito contemporâneo, onde se verificará a visão sistêmica de Niklas Luhmann, sem o intuito de esgotá-la, visando analisar a contribuição da referida teoria para a dogmática jurídica, especificamente no âmbito da Responsabilidade Civil, no que concerne a tomada de decisões que envolvam situações complexas e de risco, restringindo a complexidade de causalidades não bem definidas.

\section{2- A TEORIA SISTÊMICA DE NIKLAS LUHMANN E A SUA CONTRIBUIÇÃO PARA A CIÊNCIA DO DIREITO}

\section{1- CONSIDERAÇÕES SOBRE O AUTOR}

Niklas Luhmann nasceu em Lüneburg, Alemanha, em 1927. Dedicou-se a um projeto ambicioso que consistiu em criar uma teoria geral da sociedade que pudesse explicá-la em todas suas nuances. Sua principal obra foi intitulada A sociedade da sociedade, cuja intenção era agregar um espírito multidisciplinar à sociologia, com conceitos de diversas áreas do conhecimento (biologia, cibernética, lógica), a fim de embasar um teoria sociológica unificadora. Estudou direito em Freiburg em 1946 e ingressou no serviço público em Lüneburg. Em meados de 1962 recebeu uma bolsa de estudos administração pública em Harvard, onde conheceu Talcott Parsons, sociólogo americano, e foi apresentado à sociologia estruturalfuncionalista. Entre 1965 e 1968 se doutorou em Münster e se tornou professor de sociologia na Universität Bielefeld, onde permaneceu até 1993, quando se aposentou como professor, sem, no entanto, esgotar sua produção científica. Faleceu em 1998, pouco antes de completar 71 anos.

O problema central de sua análise é a complexidade, que significa a totalidade dos possíveis acontecimentos e das circunstâncias: algo é complexo, quando, no mínimo, envolve mais de uma circunstância. Com o crescimento do número de possibilidades, cresce igualmente o número de relações entre os elementos, logo, cresce a complexidade (LUHMANN, 1973, p 11). 
Tal complexidade extrema do mundo, não capaz é de ser compreensível pela consciência humana, pois o homem não possui capacidade de dar conta da captação da complexidade, sobretudo se observar todos os possíveis acontecimentos e todas as circunstâncias no mundo. Desse modo, entre a extrema complexidade do mundo e a consciência humana há um hiato. E é justamente aí que os sistemas sociais manifestam a função de redução de complexidade, pois intervêm entre a extrema complexidade do mundo e a limitada capacidade do homem em trabalhar a complexidade (Op. Cit, p. 13).

\section{2- A TEORIA DOS SISTEMAS}

A teoria sistêmica de Niklas Luhmann pretende explicar a sociedade como um sistema social, que requer a operação de diferentes subsistemas, como a religião, a economia, o direito, que se fragmentam em subsistemas presdispondo a complexidade e a dupla contingência. Caso se consiga entender como a relação entre os indivíduos gera um sistema, poderá tentar compreender se e como esse sistema formado se apresenta como paradoxal, segundo sugere Luhmann. O caminho elucidativo para construir essa ponte teórica reside no entendimento do que Luhmann chama de dupla contingência. No seu intento apresenta um possível caminho para se estabelecer a ordem a partir do caos (MADEIRA, 2007, p 28).

Para a melhor compreensão da referida teoria, é mister explanar seus pressupostos, isto é, as premissas metodológicas básicas, quais sejam: a relação sistema/ambiente, a autopoiese e a complexidade, dupla contingência e a comunicação.

Quanto à relação sistema/ambiente, Luhmann entende que o sistema somente se estabelece com base na diferença com seu ambiente. Na verdade, as diferenças alinham toda a sua teoria: Sistema/ambiente, meio/forma, atualidade/possibilidade, lícito/ilícito, governo/oposição, nada é trazido a estudo sem que seu oposto, o outro lado da forma, o acompanhe. Sem diferença não pode existir relação, unidade, complexidade, sistema, observação. (LUHMANN, 1994, p. 27).

A relação entre o sistema e o ambiente é fundamental para caracterizar o sistema e o sistema se define sempre a partir do ambiente, como bem elucida Luhmman ( Op. Cit, p.

entre hombre y sociedad se da la relación existente entre un sistema y su entorno. Una relación inmensamente fecunda cuando se trata de un sistema autorreferente y que obliga a pensar de modo nuevo categorias aceptadas 


\begin{abstract}
desde antiguo y aplicada, a veces, sin rigor, al análisis de la sociedad contemporánea. La sociedad compuesta de comunicaciones, se diferencia internamente, ségun su grado evolución e desarollo, en diferentes subsistemas sociales. Cada uno de estos subsistemas sociales es, como he indicado, um sistema autorreferente y autopoiético y tiene a lós demas subsistemas como su entorno, manteniendo su clausura y su própria independência.
\end{abstract}

. Nesta seara, o sistema é definido por sua diferença com relação ao ambiente, o que inclui na sua constituição sempre a diferença a respeito do ambiente e somente pode ser bem entendido a partir dessa diferença. O autor identifica, de uma maneira geral, a existência de quatro tipos de sistema no mundo: os não-vivos, os vivos, os psíquicos e os sociais, sendo somente os três últimos que ganham destaque na teoria sistêmica aduzida pelo autor, uma vez que são sistemas autopoiéticos, ou seja, capazes de se autoproduzir (Op.Cit, p. 24).

Vale ressaltar que, contendo a diferença, o sistema é autopoiético, autorreferente e operacionalmente fechado, reduzindo a complexidade do entorno. Entretanto, se ele opera para a redução da complexidade, ao mesmo tempo, também constrói sua própria complexidade, daí a necessidade de se fechar operacionalmente em relação ao entorno, produzindo seus próprios elementos, (autopoiésis) operando, assim, a construção de sua própria complexidade. E é neste processo que ocorre a evolução: que o sistema evolui com o objetivo de sobreviver à complexidade criada com as contingências inesperadas do seu meio, impulsionando-o a uma reforma, que não pode ser planejada, visto que ela se nutre dos desvios da reprodução normal (NEVES, 2006, p. 192).

Luhmann considera que o entorno é sempre mais complexo que o sistema: abarca todas as possíveis relações, acontecimentos e processos. Uma das diferenças entre sistema e entorno se verifica quando aquele passa a operar seletivamente, seja no plano das estruturas, seja no plano dos processos. Gize-se que, para ele, sempre existem outras possibilidades que se possam selecionar quando se busca uma ordem. Justamente porque o sistema seleciona uma ordem, ele mesmo se torna complexo, já que se obriga a fazer uma seleção da relação entre seus elementos (Op. Cit. p. 194).

Em entendimento semelhante, Edgar Morin (2002, p.47) assevera que nos diferentes domínios do conhecimento, as noções de ordem e desordem exigem cada vez mais que sejam concebidas de forma complementar e não meramente antagônicas, apesar de todas as dificuldades que essa relação envolva. 
Nesse diapasão, para Luhmann, em uma sociedade complexa e contingente, as possibilidades de comportamento social exigem reduções que tendem a possibilitar a manutenção de expectativas comportamentais recíprocas, as quais são orientadas a partir das expectativas sobre expectativas.

Niklas Luhmann se utiliza dos conceitos de contingência e complexidade, onde esta significa que sempre existem mais possibilidades do que se pode realizar, enquanto aquela consiste no fato de que as possibilidades apontadas para as demais experiências poderiam ser diferentes das esperadas. A complexidade entendida por um estado em que não se pode mais relacionar todos os elementos entre si, em que há um excesso de possibilidades de combinação, leva à seleção contingente, de modo que para que uma operação continuar, é necessário selecionar uma opção de relação entre os elementos. Podemos, então, concluir que complexidade significa seleção forçada, e contingência significa perigo de desapontamento e necessidade de se assumir riscos (LUHMANN, 2005, p.14)

Esta seleção vinculará as seguintes, reduzindo, assim, a complexidade. Esta redução não é necessariamente benéfica ao sistema, pois, se por um lado, a complexidade apresenta uma infinidade de possibilidades de seleção, provocando a seleção e, portanto, o risco, por outro confere adaptabilidade às relações entre elementos. Os sistemas precisam compensar esta redução de complexidade com uma seletividade organizada, tornando a complexidade estruturada Assim, através deste controle, seriam reduzidos os riscos de frustrações de expectativas (Op. Cit, p.14).

O fato é que somente se dispõe uma contenção de expectativas na medida em que as interações entre indivíduos passam a fazer parte do sistema social através da comunicação, transcendendo a esfera subjetiva do psiquismo. Ou seja, é através da comunicação que se permite transcender a esfera da psique individual. Como explica Dalmir Lopes Junior (2004, p. 11):

O sistema social tem por base a incerteza, a necessidade de controlá-las é o que leva os sistemas a se resguardarem através de estruturas, que acabam por informar o comportamento adequado para cada situação, de forma a absorveresse incerteza da dupla contingência e permite a seleção de umcomportamento dentro da complexidade do possível.

Nessa linha de raciocínio, toda escolha é uma contingência do possível e expõe um risco. Daí porque é fundamental que os sistemas sociais disponham de estratégias que controle a ansiedade do risco oriundo das possíveis frustrações. Não é difícil perceber, então, que 
as normas jurídicas assumem uma função essencial nesse cenário, já que representam a garantia mais eficaz da confiança, além de representarem expectativas normativas, ou seja, em geral, não são passiveis de defraudações.

Basta analisarmos a sanção/ameaça de sanção: o direito resgataria as expectativas frustradas e exerceria sua função sistêmica tão bem designada por Luhmann: a manutenção das expectativas normativas. É através da diferenciação entre o normativo e o cognitivo que o sistema jurídico poderia se diferenciar de seu entorno.

\section{3- O DIREITO COMO SUBSISTEMA}

No interior da sociedade há diversos subsistemas e o Direito pode ser considerado um deles, juntamente com a política e economia, etc., cada qual com seu tipo específico de comunicação. Os sistemas sociais possuem dupla função: mediam a complexidade do mundo (ambiente) e a limitada capacidade do homem em assimilar as formas de vivência e buscam reduzir a complexidade, selecionando as possibilidades do mundo a partir de critérios internos ao sistema. Essa complexidade da sociedade moderna encerra a preocupação fundamental de Luhmann: o problema da ordem social. É sob tal égide que se assenta o subsistema Direito (MADEIRA, 2007, p. 27).

Para Luhmann, o direito está apoiado em valores como a sua responsabilidade social e o seu funcionamento sem atritos. Para ele, a norma fundamental do Estado de Direito é vista como um valor, como uma aquisição civilizacional. Assim sendo, o direito pode ser mudado apenas entre de seus próprios limites. O sistema jurídico se apresenta apropriado de regras de procedimento cuja conexão com a hierarquia material deve continuar obscurecida (Op. Cit. p. 33).

Cabe ressaltar, que para o autor alemão, o direito, apesar de ser exposto como uma estrutura, mostra-se dinâmico em virtude da sua constante premência de atualização, pois conforme a sua função, deve agir para reduzir a complexidade das possibilidades de ser no mundo. A teoria sistêmica do direito, ao comunicar a norma jurídica com o sistema social e a práxis significativa, fornece um importante passo para a construção de uma nova teoria do Direito. Esta, por sua vez, aborda simultaneamente os seus aspectos analíticos, hermenêuticos e pragmáticos, em relação ao sistema social (ROCHA, 2006, p.252).

Assim como os demais sistemas sociais, o direito para Luhmann, constitui-se de experiências que passam por possibilidades de complexidade e contingência, donde surgem 
expectativas que podem ser tomadas cognitivamente ou normativamente. Enquanto que a complexidade gera, forçadamente, a necessidade de uma seleção de possibilidades, no sentido de reduzir o âmbito de experiências a fim de que elas possam ser lidas pelo sistema e geridas autopoeticamente, permitindo seu fechamento operacional e consequente distinção do entorno e autorreferência. A contingência carrega consigo o perigo do desapontamento quanto às expectativas geradas em relação às possibilidades previstas, e uma consequente necessidade de assumir o risco (LUHMANN, 1983, p.45).

É nesse sentido que funciona o sistema do direito, no sentido de coordenar, controlar a contingência, diminuir o risco. Se, por exemplo, a ocorrência de danos futuros é um dos riscos de uma sociedade que não consegue prever a iniciativa de seus integrantes, quanto ao cumprimento de condutas sempre conforme o direito, adotando todas as medidas de prevenção possíveis, compete ao sistema jurídico domar essa expectativa, controlando o risco, evitando ou mitigando o desapontamento, como ocorre no caso, das presunções de causalidade, cuja hipótese clara pode ser retirada do direito ambiental, vez que o lapso temporal entre o dano e o evento danoso, em regra, é enorme, a dificultar a comprovação dos fatos oriundos da poluição, que possuem natureza complexa e efeitos difusos concorrentes com outras fontes poluidoras, configurativas de uma causalidade complexa (MALHEIROS,

2013, p.186).

Ademais, na visão sistêmica, o direito surge porque determinadas expectativas sociais são selecionadas a fim de lidar com a decepção normativa. A estrutura do sistema jurídico é formada quando uma quantidade de expectativas é generalizada de maneira temporal, social e objetiva, formando um corpus normativo. A expectativa tem que ser lidadas como um dever coativo, ao qual, em caso de descumprimento, pela decepção gerada, seja estabelecida uma sanção, que garanta uma reação ao desapontamento, permitindo a manutenção da expectativa, mesmo sob a ameaça dos riscos (ROCHA, 2006, p.234).

Nessa senda, considerando a dimensão temporal, as expectativas são estabelecidas contra frustrações, por meio da normatização e da generalização, viabiliza-se uma maior segurança contra frustrações. Assim, Luhmann (1983, p. 52) afirma que a normatização dá continuidade a uma expectativa, independente do fato de que ela de tempos em tempos venha a ser frustada. 
Portanto, sendo o direito, texto que é, portanto linguagem, entende-se a explicação do direito como sistema de sentido, ou seja, como comunicação, pois comunicação é célula da sociedade; sociedade é sistema que estabelece sentido; sentido é operação de comunicação (Op. Cit. p.151).

Buscando dar concretude à temática própria deste artigo e analisando a estrutura do sistema jurídico brasileiro, dialogando com a Teoria sistêmica de Luhmann, pode-se dizer que,no que tocante à responsabilidade civil, o quadro sistemático se apresenta da seguinte maneira: da sociedade (sistema social de primeiro grau), forma-se o Direito (sistema social de segundo grau) autonomizado por seu código comunicacional próprio, isto é, legalilegal. Dentro do Direito e dependente dele, tem-se a emergência de sistemas menores (ramos da dogmática jurídica, por exemplo, o direito civil). Derivando-se do direito civil como sistema que, ao lado do código legal/ilegal, vale-se de um código próprio (direito comumldireito especial) para determinar o que faz e o que não faz parte da sua substância, pode-se descender ao sistema de direito das obrigações, cujo código comunicacional é adimplemento/inadimplemento (lega1/ilegal especificado em comum/incomum e em adimplemento/inadimplemento). Do sistema obrigacional, chega-se ao sistema de responsabilidade civil, que dele se emancipou.

No tópico subsequente, abordaremos os pontos de contato entre a Teoria dos sistemas de Luhmann e a Responsabilidade Civil, no que tange ao risco de danos futuros e o problema da imputação da responsabilidade nestes casos.

\section{3- UM NOVO OLHAR PARA O RISCO E A IMPUTAÇÃO DA RESPONSABILIDADE POR DANOS FUTUROS}

Conforme exposto, o direito exerce o papel redutor da complexidade e da contingência que é própria das sociedades contemporâneas. Sucede-se na qualidade de instância temporal de garantia das expectativas sociais mediante imputações objetivas procedimentais que, além de discriminar certas condutas, tornam viáveis projeções interacionais, mesmo em contexto de dúplice contingência, estabelecendo relações e operacionalizando comportamentos.

Alerta François Ost (p.225)que

não será de surpreender que, neste contexto de fragilidade do objecto estudado e de complexidade da teoria que o explica, a ideia de incerteza faça a sua aparição. Para grande espanto dos juristas, que frequentement e imaginam que a ciência produz certezas, parece hoje que a ecologia científica fornece mais questões do que respostas seguras. 
Esse entendimento se apresenta relevante quando tratamos da causalidade em situações complexas e da imputação da responsabilidade. Se se compreende o nexo de causalidade como ligação de um efeito a uma dada causa, é possível que se esconda, sob o véu do mais simples truísmo, dificuldades teóricas e atividades de grande complexidade.

Sendo a causa e efeito elementos fundamentais da Responsabilidade Civil, a sua imputação de responsabilidade passa pela consideração da relação entre uma conduta, dano (via de regra deve ser específico) e a comprovação de relações causais entre conduta e dano. Porém, como solucionar o problema do risco ambiental ou biotecnológico se a sua exponenciação possui uma multiplicidade de causas concorrentes? Como responsabilizar se, muitas vezes, não é possível delinear especificamente o agente do dano/risco? De que maneira o sistema jurídico poderia regular o risco em um contexto no qual há uma multiplicidade de agentes/causas dificilmente identificáveis e de um dano que se proteja para o futuro?

O direito pode atuar em relação à causalidade, utilizando-a, ignorando-a ou, de certa maneira, criando-a. Porém, no mais das vezes ele importa da causação física de uma consequência e a insere em seu sistema como causação jurídica, atribuindo ao causador mecânico a causação jurídica, como quando é atribuido ao condutor do veículo o dever de reparar o dano que causou por ter colidido com veículo de um terceiro. Há casos, ainda, em que o Direito desconsidera uma dada sucessão causal natural, e deixa de atribuir a causação jurídica ao causador mecânico, a exemplo dos casos de reconhecimento de culpa exclusiva da vítima. Igualmente possível, que o Direito atribua a causação jurídica sem se valer de qualquer substrato causal natural imediato, basta citar a responsabilidade civil por omissão (VENOSA, 2013, p.107)

A questão fica mais intrincada quando se percebe que a complexidade da sociedade atual decorre das incertezas geradas nos sistemas sociais, no entanto, a dogmática jurídica está pautada na certeza e na previsibilidade, o que não comporta as exigências da sociedade de risco que retrata o contexto das contingências, tampouco opera com clareza em situações de riscos para o futuro.

Fritjof Capra (1982, p.21, 30 ) alerta para o fato de que

Efeitos menos óbvios, mas possivelmente mais perigosos, só recentemente foram reconhecidos, e ainda não foram compreendidos em toda sua extensão. Contudo, torneou-se claro que a nossa tecnologia está perturbando seriamente e até pode estar destruindo os sistemas de que depende nossa existência (...) A transformação que estamos vivenciando agora, poderámuito bem ser mais dramática do que qualquer das precedentes, porque o ritmo da mudança em nosso tempo é mais célere do que no passado, porque as mudanças 
são mais amplas, envolvendo o globo inteiro, e porque as várias transições importantes estão coincidindo.

O já mencionado conjunto conduta-nexo-dano não mais possui a capacidade de se concatenar diante de eventos altamente complexos, como aqueles relacionados ao risco, com a possibilidade de danos a longo prazo decorrentes da união de múltiplas causalidades concorrentes, o que promove nítidas dificuldades teóricas para a imputação de responsabilidade. (SCHREIBER, 2013, p. 55).

Pelo menos nos sistemas sociais, a causalidade deve ser compreendida como procedimento seletivo realizado com vistas a certos interesses, é sempre uma seleção que se deve atribuir a um observador com determinados interesses, com um tipo específico de estrutura de observação, e com uma capacidade bastante determinada de processar informação. A articulação entre causas e efeitos realizada por um observador depende dos interesses com que ordena o objeto, ou na medida em que confere importância a determinados efeitos, e o risco, nesse contexto, depende sempre de uma tomada de decisão, ou seja, o processo de decidir se transforma em risco. (LUHMANN, 2009, p. 104).

É justamente a decisão que difere o risco do perigo. Em apertada síntese, Luhmann entende que a decisão tomada diante de uma situação de perigo poderá gerar a existência do risco. De modo exemplificativo, a inundação é um perigo, porém, o indivíduo que ergue sua casa no leito de um rio se expõe a um risco. De modo semelhante, o cigarro constitui um perigo, mas aquele que decide consumir se encontra em uma situação de risco.

Para Winter de Carvalho (2008, p.71)

A passagem de uma teoria do risco concreto (ou dogmático) para uma teoria do risco abstrato (proveniente das teorias sociais de autores como Niklas Luhmann, Raffaele de Giorgi, Ulrick Beck) decorre da própria mutação da sociedade, ou seja, da transição de uma sociedade industrial para uma sociedade de risco, na qual as indústrias químicas e atômica demarcam uma produção de riscos globais, invisíveis e de consequências ambientais imprevisíveis, enquanto os riscos da sociedade industrial são concretos (fumo, trânsito, utilização industrial de máquinas de corte etc.), os riscos inerentes à sociedade de risco são demarcados por sua invisibilidade, globalidade e imprevisibilidade. Os riscos invisíveis, surgidos em acréscimo aos riscos concretos, apresentam uma nova face, isto é, são imperceptíveis aos sentidos humanos (visão, olfato, tato, audição e gustação). Em que pes e o risco tratar-se 
de uma construção social, essa nova formatação social ressalta a importância do futuro, na qual deve haver sempre a avaliação das consequências futuras das atividades humanas.

O novo olhar da sociedade complexa proporcionado pela teoria dos sistemas sociais de Luhmann, aborda as contingências e as indeterminações como fatores importantes à análise social. A ideia de sistema é que tudo está interrelacionado, e, evidentemente, essa teoria implica a comunicação com o Direito, pois esse está inserido num sistema social que é complexo e contingente. Nesse sentido,o processo de causalidade não é linear como imaginava a ciência clássica, mas circular e inter-relacional, de modo que os elementos de causalidade atuam reciprocamente uns sobre os outros de forma aleatória (CUNHA, 2006, p. 231).

A partir da ideia de risco, fomenta-se a noção de prevenção. Assim, deverão ser normativamente imputados os danos que excederem a confiança e ultrapassarem o risco aceitável pela sociedade. A confiança é conceituada por Luhmann como um instrumento em que os indivíduos reduzem a complexidade interna do seu sistema de interação, adotando expectativas específicas sobre o comportamento futuro de outros pela seleção de possibilidades, podendo basear-se em processos históricos, em características compartilhadas ou em mecanismos institucionais (OLIVEIRA, 2007, p.38).

No tocante a prevenção, Luhmann entende que ela é o modo muito geral de preparação de danos incertos, direcionada à redução tanto da probabilidade que se verifique um dano, quanto do seu calcular. A prevenção pode, portanto, ser praticada seja no caso do perigo, seja no caso do risco. Pode-se armar também dos perigos que não se atribuem às próprias decisões; exercita-se no uso das armas, coloca-se pela parte de somas em dinheiro, ou confia-se em amigos, aos quais se pede, eventualmente, ajuda. Semelhantes estratégias de segurança são colaterais e são motivadas geralmente pelas inseguranças próprias da conduta da vida neste modo (PEREIRA, 2006, p.182).

Pode-se dizer que as condutas na sociedade devem fazer nascer expectativas legítimas naqueles em que se desperta confiança. O consumidor, quando se decide por determinado serviço, produto ou oferta, é porque foi despertada sua confiança, confiança, inclusive, de não ter expectativas frustradas por ocasião de danos. Assim, para Luhmann a confiança é umelemento central ou suporte fático da vida em sociedade, que em sentido mais amplo da palavra reside da própria expectativa, nos elementos e na normalidade dos fatos sociais, constituindo, portanto, um fator redutor da complexidade. 
Mas se o risco está presente em todas as circunstâncias e dependerá de uma tomada de decisão e de uma avaliação do observador acerca da relação temporal para que the seja proporcionada a possibilidade de tomadas de decisões com menor potencial de risco futuro e, consequentemente, com menor afetação difusa, evitando o abalo na confiança, um evento indeterminado de situações que não podem ser identificadas pelo conhecimento técnico, fazem com que a observação realizada pelo julgador não disponha de elementos seguros para estabelecer o nexo causal, motivo pelo qual o risco supera os ditames causais, abrindo oportunidades a um novo contexto de responsabilidades sobre as ameaças (SIMIONI, 2006, p.7).

A superação do risco pode, inclusive, coincidir situações altamente improváveis onde duas ou mais relações causais se unam de forma inesperada, promovendo eventos imprevisíveis, onde a tradicional solução jurídica levaria à ausência de responsabilização por danos, tampouco por riscos, eis que o Direito na responsabilidade civil tradicional não alcançaria a relação de causalidade, sinalizando que em situações de multiplicidade de causas concorrentes para o risco, é urgente a criação de mecanismos coletivos para a gestão de risco e imputação objetiva de responsabilidade.

Um caso paradigmático foi submetido a julgamento na Holanda. Pesquisadores descobriram vínculo estatístico entre a utilização da substância “diethylstilbestrol” (DES), em mulheres grávidas - indicado para evitar nascimento prematuro- e a formação de câncer urogenital em meninas, filhas de mulheres que ingeriram a droga durante a gravidez. Apesar de os autores não especificaram as empresas farmacêuticas que efetivamente comercializaram o produto na época de formação da doença, eles provaram que havia um conjunto de possíveis companhias que fabricaram o remédio. Desse modo, a Suprema Corte holandesa condenou à responsabilidade solidária as companhias farmacêuticas que comercializaram o produto na época, de tal forma que, na condenação, não se mantivesse um viés individual. Uma vez que as companhias puseram,em determinado período, o produto no mercado,e, considerando-se que o produto causou efetivamente dano, as empresas deveria arcar com a reparação (MALHEIROS, 2013, p. 185).

No, Brasil, entretanto, ainda há resistência e dificuldade de enfrentar situação como a supracitada. O um caso com idêntico problema jurídico, julgado no RESP 720.930, cujo relatório foi o Luis Felipe Salomão, o STF negou o dever de reparar, imputado ao fabricante, pela não comprovação da ingestão dos aludidos placebos pela autora, além de ser fundamentado na ausência de demonstração do nexo causal, o qual passaria, necessariamente, pela demonstração ao menos da aquisição dos indigitados placebos, o que não ocorreu. 
Observa-se que, os possíveis caminhos da responsabilidade civil devem passar por um alargamento das estruturas dogmáticas do sistema jurídico e pela necessidade de observações complexas e, por isso, igualmente arriscadas; é necessário, pois, um Direito cuja abertura cognitiva torne possível e capaz de observar seu entorno, dialogando com uma multiplicidade de discursos sociais e, observando, construtivamente, possibilidades para uma sociedade na qual não mais é possível a univocidade da razão (ALVES, 2013, p. 181).

O Direito contemporâneo, por isso, deve observar outros sistemas sociais/organizacionais, buscando, pelo meio normativo/decisional, não a utopia pandectista de um marco regulatório a partir do qual todas as situações possam ser previamente delimitadas, mas sim a viabilização de ressonâncias (nos demais âmbitos comunicativos da sociedade. É justamente a possibilidade de abertura pelo seu fechamento que evidencia possibilidades construtivistas para o direito de responsabilidade (Op. Cit, p. 179).

\section{5- CONSIDERAÇÕES FINAIS}

A pesquisa para a elaboração deste artigo foi desenvolvida foi no intuito de despertar maior interesse no estudo de um autor atual como Niklas Luhmann, cuja teoria é pouco abordada no meio acadêmico brasileiro. Conforme afirmado, não o objetivo não era esgotar todos os debates que o tema levanta, mas ao revés, buscar relações entre a teoria para aclarar as nuances da sociedade complexa e de risco.

Enquanto a Responsabilidade Civil vêm sendo tratada ao longo dos anos sob um viés restrito às relações humanas privadas, a teoria dos sistemas de Luhmann busca analisar o conjunto destas relações sob uma perspectiva mais abrangente, sistêmica e social.

Nesse contexto, é imprescindível estudar, dentro do cenário da incerteza, do risco, da complexidade e das contingências, possibilidades de comportamento social que reduzam a complexidade e possibilitem a manter expectativas comportamentais recíprocas, conforme propôs Niklas Luhmann.

Podemos verificar que, o direito, apesar de ser exposto como uma estrutura, mostra-se dinâmico em virtude da sua constante premência de atualização, deve agir para reduzir a complexidade. Ao comunicar a norma jurídica com o sistema social e a práxis significativa,fornece um importante passo para a construção de uma nova teoria do Direito. 
A teoria de Luhmann se mostra relevante ao dialogar sua proposta com o estudo da causalidade em situações complexas e da imputação da responsabilidade, pois embora o risco esteja presente em diversas situações da sociedade atual, ele dependerá de uma tomada de decisão e de uma avaliação acerca da relação temporal para que lhe seja proporcionada a possibilidade de tomadas de decisões com menor potencial de risco e danos futuros.

Como relação de causalidade, em situações de risco e complexidade é difícil de ser alcançada, é importante aprofundar debates científicos sobre a criação de mecanismos coletivos para a gestão de risco e imputação objetiva de responsabilidade.

\section{6- REFERÊNCIAS BIBLIOGRÁFICAS}

ALVES, Paub Roberto Ramos. Gestão jurídico-organizacional do risco biotecnológico: auto-organização e responsabilidade coletiva. Revista Brasileira de Direito, IMED, Vol. 9, nº 1, jan-jun 2013.

CARVALHO, Délton Winter de. Dano ambiental futuro: a responsabilização civil pelo risco ambiental. Rio de Janeiro: Forense Universitária, 2008.

CAPRA, Fritjof. O ponto de mutação. São Paulo: Ed. Círculo do Livro, 1982.

CRUZ, Gisela Sampaio da. O problema do nexo causal na Responsabilidade Civil. Rio de Janeiro. Renovar. 2005.

LEVY, Daniel de Andrade. Responsabilidade civil: de um direito de danos a um direito das condutas lesivas. São Paulo. Atlas, 2012.

LOPES JR. Dalmir. Niklas Luhmann: do sistema social à sociologia jurídica. Rio de Janeiro. Lúmen Júris, 2004.

LUHMANN, Niklas Introdução à teoria dos sistemas. Trad. Ana Cristina Arantes Nasser, Petrópolis, Editora Vozes, 2009.

_ Ilustración Sociológica y otros ensayos. Sur, Buenos Aires, 1973, p.11.

_ Sociedad y sistema: la ambición de la teoría. 1. Reimpresión, Buenos Aires -

México: ICE, 1994.

Organización y decisión in Organización y decisión. Autopoiesis, acción y entendimiento comunicativo, $1^{\text {a }}$ Ed. $1^{\text {a }}$ reimp, Barcelona: Anthropos, México: Iberoamericana, 2005.

MADEIRA, Lígia Mori. O Direito nas Teorias Sociológicas de Pierre Bourdieu e Niklas 
Luhmann. Direito \& Justiça, Porto Alegre, v. 33, n. 1, p. 28, junho 2007.

MALHEIROS, Pablo Malheiros da Cunha. A imputação sem nexo causal e a respons abilidade por danos. Curitiba. Juruá. 2013.

MORIN, Edgar. Educação e complexidade: os sete saberes e outros ensaios. São Paulo: Cortez, 2002.

NEVES, Clarissa Eckert Baerta. O que há de complexo no mundo complexo? Niklas Luhmann e a Teoria dos Sistemas Sociais. Revista Sociologias. Porto Alegre, ano 8, $\mathrm{n}^{\circ}$ 15, jan/jun, 2006.

OLIVEIRA, Ana Perestrelo de. Causalidade e imputação na responsabilidade civil ambiental. Coimbra: Almedina, 2007.

ROCHA, Leonel Severo. Niklas Luhmann. Dicionário de Filosofia do Direito. Coord. Vicente de Paub Barreto. Rio de Janeiro: Renovar, 2006.

SCHREIBER, Anderson. Novos paradigmas da responsabilidade civil: da e rosão dos filtros da reparação à diluição dos danos. 5 ed. São Paulo. Atlas. 2013.

SIMIONI, Rafael Lazzarotto. Direito Ambiental e s ustentabilidade. Curitiba: Juruá, 2006. VENOSA, Silvio de Salvo. Direito civil: Responsabilidade Civil. 13 Ed. São Paulo. Atlas.2013.

OST, François. A Natureza à margem da lei: a ecologia à prova do direito. Lisboa: Instituto Piaget, 1995.

RICARDO CUNHA, JOSÉ. Direito e complexidade. BARRETO, Vicente de Paulo (COORD.). Dicionário de filosofia do direito. São Leopoldo: Ed. UNISINOS, 2006. PEREIRA, Alexandre Pimenta Batista. Os confins da responsabilidade objetiva nos horizontes da sociologia do risco: Almejando a permanente certeza na contingência das improbabilidades. Brasilia. v.43 n. 170 abr./jun. 2006. 